\title{
CD8+ T Cell-Mediated Cytotoxicity toward Schwann Cells Promotes Diabetic Peripheral Neuropathy
}

\author{
Wei Tang Qian Lv Xiang-fang Chen Jun-jie Zou Zhi-min Liu Yong-quan Shi
}

Department of Endocrinology, Shanghai Changzheng Hospital, Shanghai, PR China

Key Words

CD8 ${ }^{+} \mathrm{T}$ cells $\bullet$ Schwann cells $\bullet$ Cytotoxicity $\bullet$ Diabetic peripheral neuropathy $\bullet$ CXCR3

\begin{abstract}
Background: Damage to Schwann cells has been reported in the development of diabetic peripheral neuropathy (DPN), but how Schwann cells are damaged has not been elucidated. Methods: The highly expressed proteins in the PBMC of DPN patients were identified through MALDI-TOF/TOF and SELDI protein chip technology. The expression levels of CXCR3 were detected by $\mathrm{qPCR}$ and flow cytometric analysis. Transwell migration assay was to investigate the migration of $\mathrm{CD}^{+} \mathrm{T}$ cells. Western-blot analysis was to detect the levels of p38 MAP kinases pathway related proteins and TNF- $\alpha$, FasL, and PDL1. Results: Two highly expressed proteins, CXCR3 and p38, were identified. Under high glucose conditions, CXCR3 was elevated in CD8 ${ }^{+} \mathrm{T}$ cells via the activation of p38 MAP kinases. Moreover, CXCL9, CXCL10, and CXCL11 expression were induced in Schwann cells, leading to the recruitment and infiltration of $C D 8^{+} T$ cells into DPN tissues. Further study demonstrated that Schwann cells promoted activation of $\mathrm{CD} 8^{+} \mathrm{T}$ cells and induced expression of TNF- $\alpha$, FasL, and PDL1 on CD8 ${ }^{+}$T cells, in return, CD8 ${ }^{+}$T cells induced obvious apoptosis of Schwann cells. Conclusion: Our study indicates that CD8 ${ }^{+} \mathrm{T}$ cells mediate cytotoxicity toward Schwann cells and play an important role in the development of DPN.
\end{abstract}




\section{Cellular Physiology and Biochemistry}

Cell Physiol Biochem 2013;32:827-837

\begin{tabular}{l|l}
\hline DOI: $10.1159 / 000354485$ & (C) 2013 S. Karger AG, Basel
\end{tabular}

www.karger.com/cpb

828

Tang et al.: CD8 ${ }^{+}$T Cell-Mediated Cytotoxicity toward Schwann Cells and DPN

\section{Introduction}

Diabetic peripheral neuropathy (DPN) is one of the most common and debilitating microvascular complications of diabetes, with no currently effective options for therapeutic treatment [1-3]. The pathogenesis of DPN remains elusive; however, Schwann cells, myelinating cells of the peripheral nervous system, have been shown to play an important role in the pathogenesis and development of DPN [4]. Besides their roles in myelination, trophic support, and the regeneration of axons, Schwann cells exhibit immune functions, similar to the non-myelinating glia of the central nervous system (CNS) [5, 6]. These functions include the production of chemokines and cytokines, the expression of major histocompatibility complex (MHC) class II molecules and adhesion molecules, and serving as antigen presenting cells [7]. They also produce macrophage inflammatory protein-1a and recruit macrophages from peripheral blood vessels to local inflammation lesions [8]. Abnormalities of Schwann cells caused by hyperglycemia can cause nerve dysfunctions, such as reduced nerve conduction velocity, axonal atrophy, and impaired axonal regeneration $[4,9,10]$. However, answers for how abnormalities of Schwann cells are caused have remained elusive.

Previous studies have shown that monocytes/macrophages/T cells play key roles in the initiation, progression, and final destruction of $\beta$ cells in diabetic animals [11]. Furthermore, it has been reported that macrophages play an important role in the progression of diabetic neuropathy through secreting tumor necrosis factor- $\alpha$ (TNF- $\alpha$ ) [12]. CD8 ${ }^{+}$T cells recognize antigens through MHC class I molecules and are predominantly cytotoxic $\mathrm{T}$ cells with various mechanisms to kill their targets, including direct cell-cell signaling via surface molecules and indirect signaling via cytokines, such as TNF- $\alpha$, interleukin-1 $\beta$ (IL-1 $\beta$ ), interferon- $\gamma$ (IFN- $\gamma$ ). Whereas whether $\mathrm{T}$ cells participates in the progression of diabetic neuropathy has not been investigate clearly.

Recent studies have indicated that the chemokines CXCL9, CXCL1,0 and CXCL11 can be induced by inflammatory cytokines (such as IFN- $\gamma$ and TNF- $\alpha$ ) and that their expression is crucial for T cell trafficking, chemotaxis, and activation [13]. The CXCR3 receptor, which recognizes CXCL9, CXCL10, and CXCL11, is functionally expressed on activated T and B cells, NK cells, and endothelial cells [13]. While the infiltration of inflammatory cells into DPN tissues plays a critical role in the development of DPN, it is important to investigate whether high glucose levels can promote the expression of CXCL9, CXCL10, and CXCL11 in Schwann cells.

In the current study, we observed an elevation in CXCR3 expression on CD8 ${ }^{+} \mathrm{T}$ cells under high glucose conditions. High glucose levels also induced the expression of CXCL9, CXCL10, and CXCL11 in Schwann cells, leading to the recruitment and infiltration of CD8 ${ }^{+}$ $\mathrm{T}$ cells into diabetic peripheral tissues and increased cytotoxicity toward Schwann cells. Our study indicates that CD8 ${ }^{+} \mathrm{T}$ cells mediate cytotoxicity toward Schwann cells and play an important role in the development of diabetic peripheral neuropathy. Therefore the blockade of the CXCR3/CXCL9, CXCL10, and CXCL11 signaling axis for inhibiting the migration of CD8 ${ }^{+}$ $\mathrm{T}$ cells may represent a new strategy for preventing the development of diabetic peripheral neuropathy.

\section{Materials and Methods}

\section{Sample preparation}

Human peripheral blood samples were collected from patients with a clinical diagnosis of diabetes and DPN as well as healthy individuals at Shanghai Changzheng Hospital. The clinical diagnostic criterias for diabetics and DPN were performed as follows. The diagnostic criteria for diabetes mellitus (DM): fasting blood glucose (FPG) $\geq 7.0 \mathrm{mmol} / \mathrm{L}$ and (or) 2 hours after glucose load blood glucose (2hPG) $\geq 11.1$ $\mathrm{mmol} / \mathrm{L}$. DPN diagnostic criteria: meeting the diagnostic criteria for diabetes mellitus and with abnormal NCV(nerve conduction velocity) examination (excluding unrelated reasons for peripheral neuropathy). The study protocol was approved by Shanghai Changzheng Hospital and written informed consent was obtained 


\section{Cellular Physiology and Biochemistry}

Cell Physiol Biochem 2013;32:827-837

DOI: 10.1159/000354485

Publisned oninne: september 20, 2013

(c) 2013 S. Karger AG, Basel

www.karger.com/cpb

Tang et al.: CD8 ${ }^{+}$T Cell-Mediated Cytotoxicity toward Schwann Cells and DPN

from all patients. The study followed the Code of Ethics of the World Medical Association. Heparinanticoagulated blood was collected and peripheral blood mononuclear cell (PBMC) was separated with Ficoll for analysis. Total proteins were extracted from PBMCs, as previously described, for further analysis [14].

Protein identification and database searching

Total proteins extracted from PBMCs were quantified using the Bio-Rad protein assay (BioRad, USA) and differentially expressed proteins identified as peaks through tandem matrix-assisted laser desorption/ionization time-of-flight (MALDITOF/TOF) mass spectrometry (Applied Biosystems, Foster City, CA, USA) [15]. The acquired peptide mass fingerprint (PMF) was submitted for database searches against the NCBInr database using the MASCOT search engine (Matrix Science, London, UK) or http://www.matrixscience.com).
Table 1. PCR primers used for cDNA amplification. Real-time PCR was carried out using the following primers

\begin{tabular}{|c|c|c|c|}
\hline \multirow[t]{2}{*}{ A } & $\beta$-actin & $\mathrm{F}$ & 5'- CTTAGTTGCGTTACACCCTTTC -3' \\
\hline & & $\mathrm{R}$ & 5'- CACCTTCACCGTTCCAGTTT -3' \\
\hline \multirow[t]{2}{*}{ B } & CXCR3 & $\mathrm{F}$ & 5'- CCACCTAGCTGTAGCAGACACG -3' \\
\hline & & $\mathrm{R}$ & 5'- TCCTGCGTAGAAGTTGATGTTGA -3' \\
\hline \multirow[t]{2}{*}{$\mathrm{C}$} & CXCL9 & $\mathrm{F}$ & 5'- TTGCTGGTTCTGATTGGAGT -3' \\
\hline & & $\mathrm{R}$ & 5'- CTTTCAAGGATTGTAGGTGG -3' \\
\hline \multirow[t]{2}{*}{$\mathrm{D}$} & CXCL10 & $\mathrm{F}$ & 5'- ТСТСССАТСАСТТСССТАСА -3' \\
\hline & & $\mathrm{R}$ & 5'- CAGGGTCAGAACATCCACTA -3' \\
\hline \multirow[t]{2}{*}{ E } & CXCL11 & $\mathrm{F}$ & 5'- AAGCAGTGAAAGTGGCAGAT -3' \\
\hline & & $\mathrm{R}$ & 5'- GATTTAGGCATCGTTGTCCT -3' \\
\hline \multirow[t]{2}{*}{ F } & CD80 & $\mathrm{F}$ & 5'- GGAAAGTGTACGCCCTGTAT -3' \\
\hline & & $\mathrm{R}$ & 5'- AAGCACCTAAGAGCAGATACG -3' \\
\hline \multirow[t]{2}{*}{ G } & CD86 & $\mathrm{F}$ & 5'- GAGGCTTAGGACTTTCCACTC -3' \\
\hline & & $\mathrm{R}$ & 5'- TCCCGTAGGACATCTGTAGG -3' \\
\hline \multirow[t]{2}{*}{$\mathrm{H}$} & MHC class I & $\mathrm{F}$ & 5'- CCAGTCACCTTTACCCGGTTTC -3' \\
\hline & & $\mathrm{R}$ & 5'- AGGTCGCAGCCATACATCCAC -3' \\
\hline
\end{tabular}

\section{Cell culture}

Human Schwann cells (ScienCell, Carlsbad, CA) were maintained in Dulbecco's Modified Eagle Medium (DMEM; Invitrogen, CA) supplemented with 10\% fetal bovine serum (FBS; Gibco,USA), 0.1\% penicillin and streptomycin (Invitrogen), and 1\% human Schwann cell supplement (ScienCell, USA) at $37^{\circ} \mathrm{C}$ in an atmosphere containing $5 \%$ carbon dioxide.

\section{Quantitative real-time PCR}

Total RNA was extracted from sorted donor monocytes, neutrophils, B cells, CD4 ${ }^{+}$T cells, PMBCs, and $\mathrm{CD}^{+} \mathrm{T}$ cells or Schwann cells at the indicated times and were subsequently reverse-transcribed using the AMV Reverse Transcription System (Takara, Japan). The quantitative real-time polymerase chain reaction (qPCR) was performed using the SYBR Green PCR mix on an ABI Prism 7900HT (Applied Biosystems, USA). Thermocycler conditions included a 2-minute incubation at $50^{\circ} \mathrm{C}$ and a $95^{\circ} \mathrm{C}$ incubation for 10 minutes; this was followed by a 2-step PCR program: $95^{\circ} \mathrm{C}$ for 15 seconds and $60^{\circ} \mathrm{C}$ for 60 seconds for 40 cycles. $\beta$-actin was used as an internal control to normalize the amount of total RNA in each sample. The primer sequences are listed in Table 1.

\section{Flow cytometric analysis}

Human peripheral blood samples were collected from patients with a clinical diagnosis of DPN and PBMC. Samples were separated with Ficoll and cells then stained with anti-CD8 and anti-CXCR3 antibodies (eBioscience, USA). Schwann cells were stained with anti-CD80, anti-CD86, and anti-MHC class I antibodies (eBioscience). All samples were measured through flow cytometry (BD Aria, BD, USA).

\section{Western blot analysis}

Cells were harvested, pelleted by centrifugation, and resuspended in lysis buffer. Equal amounts of protein $(20 \mu \mathrm{g})$ were loaded onto a 5\% acrylamide stacking gel and resolved with SDS-PAGE using a 10\% separating gel. Following the transfer of separated proteins onto a polyvinylidene difluoride membrane, the membrane was blocked and probed overnight at $4{ }^{\circ} \mathrm{C}$ with ant-p65, anti-p38, anti-pERK, and anti-pJNK antibodies (Cell Signaling, USA). The membranes were then probed for $1 \mathrm{~h}$ at room temperature with goat anti-rabbit peroxidase-conjugated IgG antibodies, and the immunoreactivity detected using Western Chemiluminescent HRP Substrate (ECL) (Millipore, USA). 


\section{Cellular Physiology and Biochemistry}

Cell Physiol Biochem 2013;32:827-837

\begin{tabular}{l|l}
\hline DOI: $10.1159 / 000354485$ & (C) 2013 S. Karger AG, Basel
\end{tabular}

www.karger.com/cpb

Tang et al.: CD8+ $\mathrm{T}$ Cell-Mediated Cytotoxicity toward Schwann Cells and DPN

Immunofluoresence

Peripheral nerve tissues from serious DPN lesions were obtained when surgery was applied for wound debridement. Frozen sections were cut and fixed with $4 \%$ paraformaldehyde, permeabilized with $0.1 \%$ (vol $/ \mathrm{vol}$ ) Triton X-100, blocked with 2\% BSA, incubated with anti-CD8 and anti-CXCR3 antibodies (DAKO, Denmark) overnight, and washed with PBST. Slides were then mounted and examined under a confocal microscope (Leica, Germany).

\section{Chemotaxis assay}

The chemotaxis analysis was performed in vitro using a commercially available 24-well modified Boyden chamber chemotaxis system (ChemoTx; NeuroProbe, USA). Schwann cells were seeded into the lower chamber in the absence or presence of high glucose $(50 \mathrm{mM})$ for 24 hours. CD8 ${ }^{+} \mathrm{T}$ cells $\left(5 \times 10^{5}\right.$ cell/well) were then placed into the upper chamber, which was separated from the lower chamber by a membrane. Chemotaxis was then allowed to proceed at $37^{\circ} \mathrm{C}$ in a $5 \% \mathrm{CO}_{2}$ incubator. Anti-CXCL9, antiCXCL10, and anti-CXCR11 or anti-CXCR3 antibodies were added to block CXCR3-CXCL9/CXCL10/CXCR11 axis-mediated chemotaxis. Three hours later, cells in the lower chamber were recovered and counted. The ratio of migrating cells was calculated by dividing the number of cells in the lower chamber by the total input cells delivered onto the upper chamber before migration.

\section{Cytolytic assay}

Schwann cells were seeded into a 12 -well plate under high glucose $(50 \mathrm{mM})$ conditions. CD8 ${ }^{+} \mathrm{T}$ cells were isolated and incubated with Schwann cells in the presence of anti-CD3 and anti-CD28 antibodies for 12 hours. The supernatant from each well was then collected for measurements of lactate dehydrogenase released using a nonradioactive cytotoxicity detection kit (Promega, USA). CD8 ${ }^{+} \mathrm{T}$ cells were collected and analyzed through flow cytometry for CD25 and CD69 expression (eBioscience).

\section{ELISA}

Schwann cells were stimulated under high glucose $(50 \mathrm{mM})$ conditions for 48 hours, the supernatants collected, and the levels of CXCL9, CXCL10, and CXCL11 determined by the enzyme-linked immunosorbent assay (ELISA, R\&D Systems, USA). TNF- $\alpha$, FasL, and PDL1 were measured in the supernatants derived from co-culture of Schwann cells and CD8 ${ }^{+} \mathrm{T}$ cells under high glucose in the presence of anti-CD3 and anti-CD28 antibodies. The ELISA was performed according to the manufacturer's instructions.

\section{Statistical analysis}

Differences between two groups were compared using the $t$ test or Wilcoxon rank test. The analysis of variance or Kruskal-Wallis test was used for statistics between multiple groups followed by the StudentNewman-Keuls or Nemeny test to compare differences between the two groups, respectively. $P$ values less than 0.05 were considered significant.

\section{Results}

CXCR3 expression is elevated in the $C D 8^{+} T$ cells of diabetic peripheral neuropathy patients We collected PBMCs from healthy donors $(n=15)$, diabetic patients $(n=48)$, and diabetic peripheral neuropathy patients $(n=48)$. Matrix-assisted laser desorption/ionization time of flight mass spectrometry (MALDI-TOF-MS) were used to determine the peaks representing differentially expressed proteins. Database retrieval (Table 2) identified the high expression of CXCR3 and p38 in the PBMCs of DPN patients, which was further verified through SELDI (Surface-Enhanced Laser Desorption/Ionization) protein chip technology (data no shown).

As CXCR3 has been reported to play important roles in T cell migration, we examined whether CXCR3 is upregulated on T cells. We isolated monocytes, neutrophils, B cells, CD4 ${ }^{+}$ $\mathrm{T}$ cells, and $\mathrm{CD}^{+} \mathrm{T}$ cells from PBMCs. The mRNA was extracted from these cells and PBMCs, respectively. We found a high mRNA expression of CXCR3 mainly on CD8 ${ }^{+} \mathrm{T}$ cells (Fig. 1A). Next, we examined the expression of CXCR3 on PBMCs from health donors, diabetic patients, and diabetic peripheral neuropathy patients. The results showed that CXCR3 expression was 
Table 2. Differentially expressed proteins identified by MALDI-TOF/TOF MS. Note: Relative molecular weight (MW); Isoelectric point (PI)

\begin{tabular}{llcccc}
\hline $\begin{array}{c}\text { Database } \\
\text { ID no. }\end{array}$ & Identified protein name & abbr. & $\begin{array}{c}\text { MASCOT } \\
\text { score }\end{array}$ & PI & MW \\
\hline gi|156523970 & Alpha-2-HS-glycoprotein precursor & AHSG & 85 & 5.34 & 39340 \\
gi|55956899 & Keratin, type I cytoskeletal 9 & KRT9 & 94 & 5.14 & 62064 \\
gi|4501989 & Alpha-fetoprotein precursor & AFP & 75 & 5.48 & 68677 \\
gi|58530845 & Zyxin & ZYX & 88 & 6.22 & 61277 \\
gi| 21594896 & Mitogen-activated protein kinase 14 & MAPK14/p38 & 79 & 5.48 & 41293 \\
gi|134244285 & Neurogenic locus notch homolog protein 3 precursor & NOTCH3 & 101 & 5.18 & 243631 \\
gi|46237594 & potassium voltage-gated channel subfamily H member 1 & KCNH1 & 97 & 7.95 & 108596 \\
gi|71824 & Zinc finger imprinted 3 & ZIM3 & 62 & 9.43 & 54497 \\
gi|510196 & Zinc finger protein 3 & ZNF3 & 73 & 7.31 & 50915 \\
gi|158138568 & C-X-C chemokine receptor type 3 isoform 2 & CXCR3 & 86 & 8.62 & 45523 \\
\hline
\end{tabular}

Fig. 1. (A) PBMCs, monocytes, neutrophils, B cells, $\mathrm{CD}^{+} \mathrm{T}$ cells, and $\mathrm{CD}^{+} \mathrm{T}$ cells were isolated from blood samples of healthy donors, diabetic patients, and diabetic peripheral neuropathy patients. Then mRNA expression of CXCR3 in these cells was measured by quantitative real-time PCR. (B) PBMCs isolated from blood samples of healthy donors, diabetic patients, and diabetic peripheral neuropathy patients were stained with anti-CD8 and anti-CXCR3 antibodies, then measured through flow cytometry.

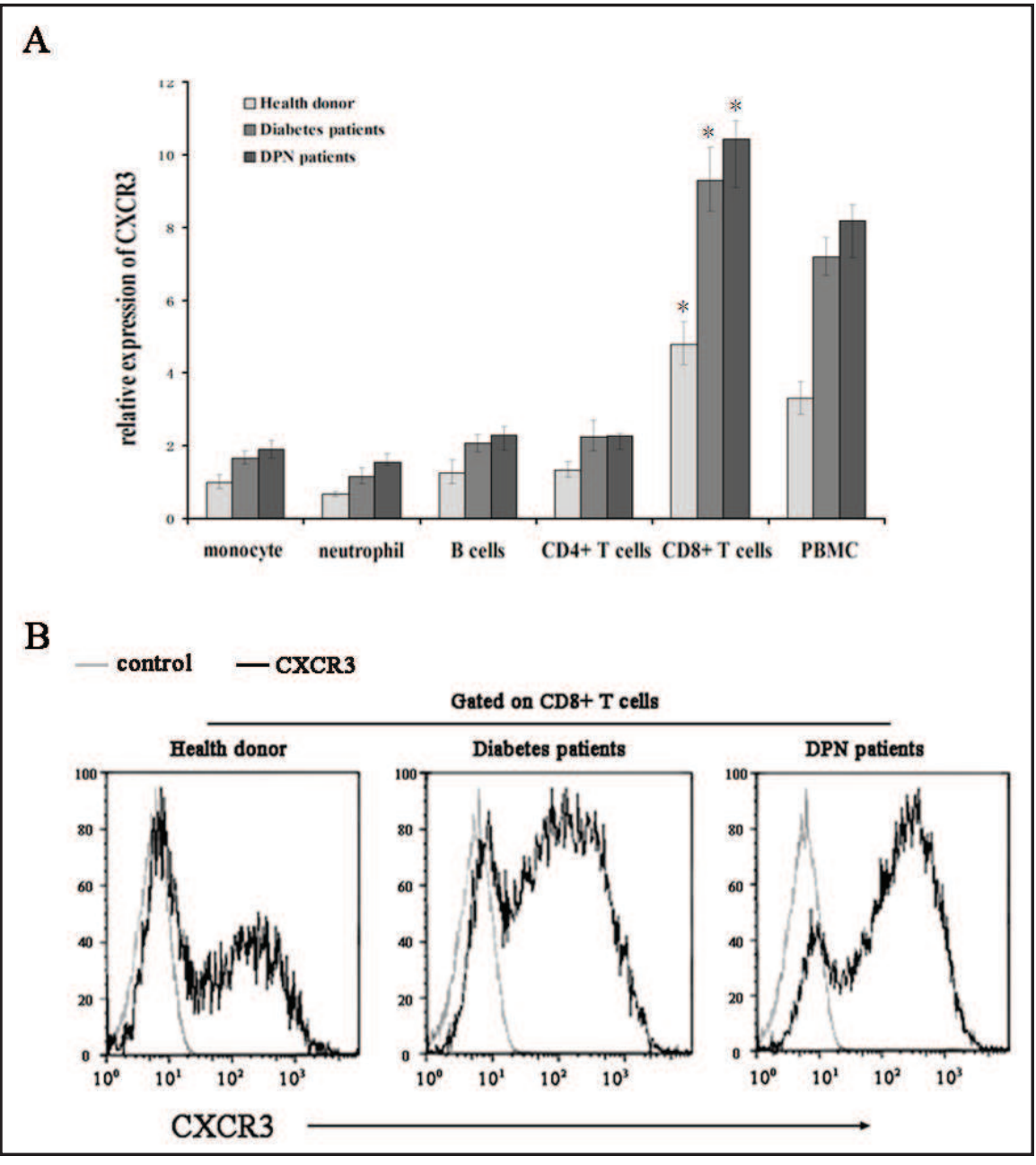

A

B

remarkably elevated on $\mathrm{CD}^{+} \mathrm{T}$ cells (Fig. 1B). All these data suggest that the expression of CXCR3 is elevated in the CD8 ${ }^{+} \mathrm{T}$ cells of diabetic peripheral neuropathy patients.

High glucose levels induce CXCR3 expression in $C D 8^{+} T$ cells via p38 MAP kinase

It has been reported that the NF- $\kappa B$ and MAP kinase pathways are involved in the regulation of CXCR3 expression and that high glucose $(50 \mathrm{mM})$ levels could also activate these pathways [16]. We therefore determined whether high glucose could induce CXCR3 expression on $\mathrm{CD} 8^{+} \mathrm{T}$ cells. $\mathrm{CD} 8^{+} \mathrm{T}$ cells were isolated and stimulated with different concentrations of 


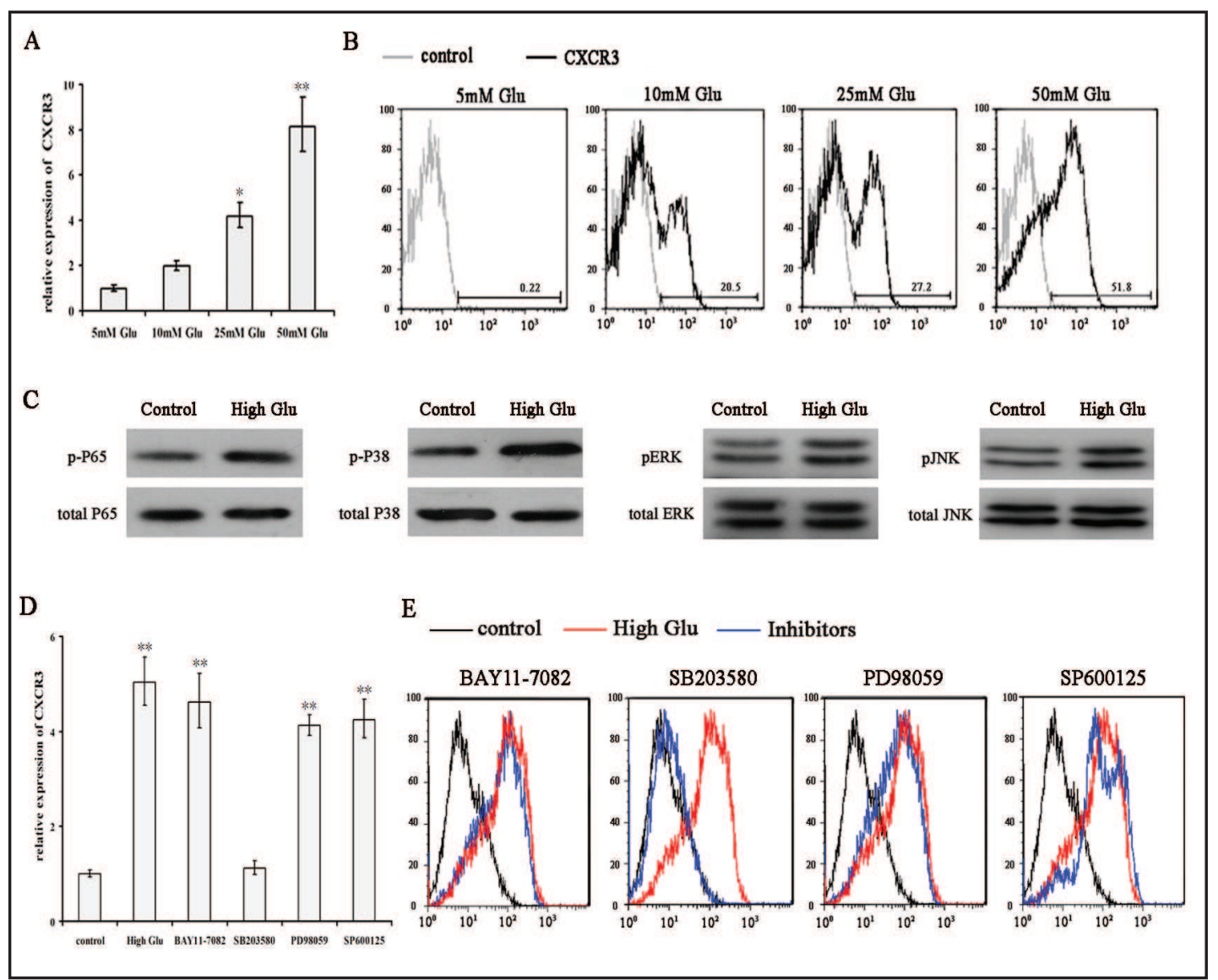

Fig. 2. $C D 8^{+} \mathrm{T}$ cells were isolated and stimulated with a high concentration of glucose $(50 \mathrm{mM})$ for 4 hours then CXCR3 expression measured by (A) quantitative real-time PCR and (B) flow cytometry. (C) Western blot analyzing the phosphorylation of p65, p38, ERK, and JNK in CD8 ${ }^{+} \mathrm{T}$ cells stimulated with high concentrations of glucose for 2 hours. $\mathrm{CD}^{+} \mathrm{T}$ cells were isolated and stimulated with a high concentration of glucose for 4 hours as well as BAY11-7082, SB203580, PD98059, or SP600125. The expression of CXCR3 was measured by (D) quantitative real-time PCR and (E) flow cytometry.

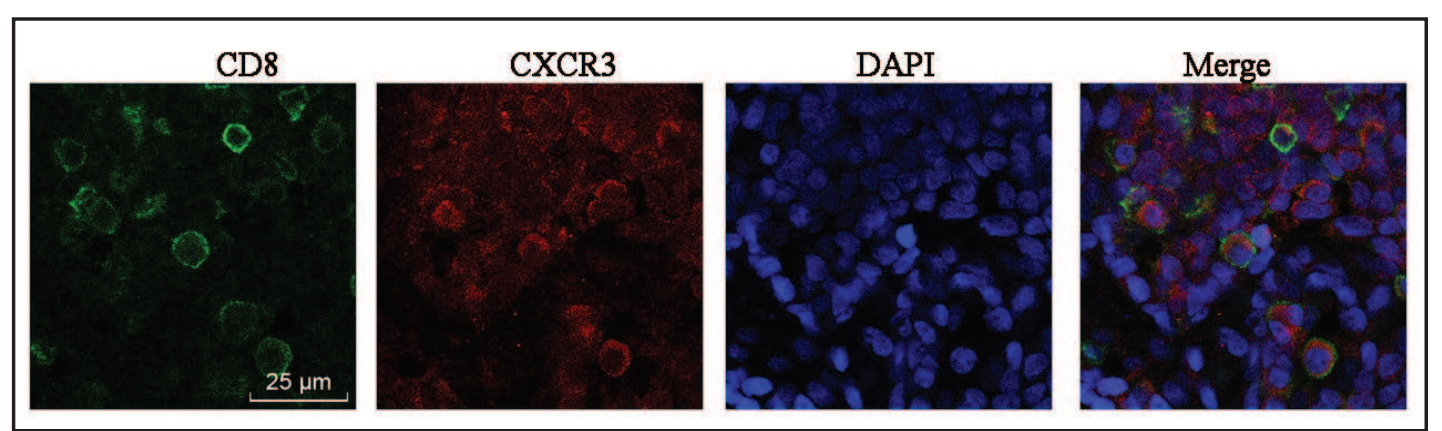

Fig. 3. Peripheral nerve tissues from serious DPN lesions were obtained when surgery was applied for wound debridement. Frozen sections stained with anti-CD8 and anti-CXCR3 antibodies were examined under a confocal microscope.

glucose (Fig. 2A). The mRNA expression of CXCR3 increased in a dose-dependent manner and CXCR3 protein expression, through flow cytometric analysis, also increased under stimulation with high glucose (Fig. 2B) concentrations. Next, we investigated whether high glucose levels could activate the NF- $\mathrm{BB}$ and MAP kinase pathways. Our data showed that the 


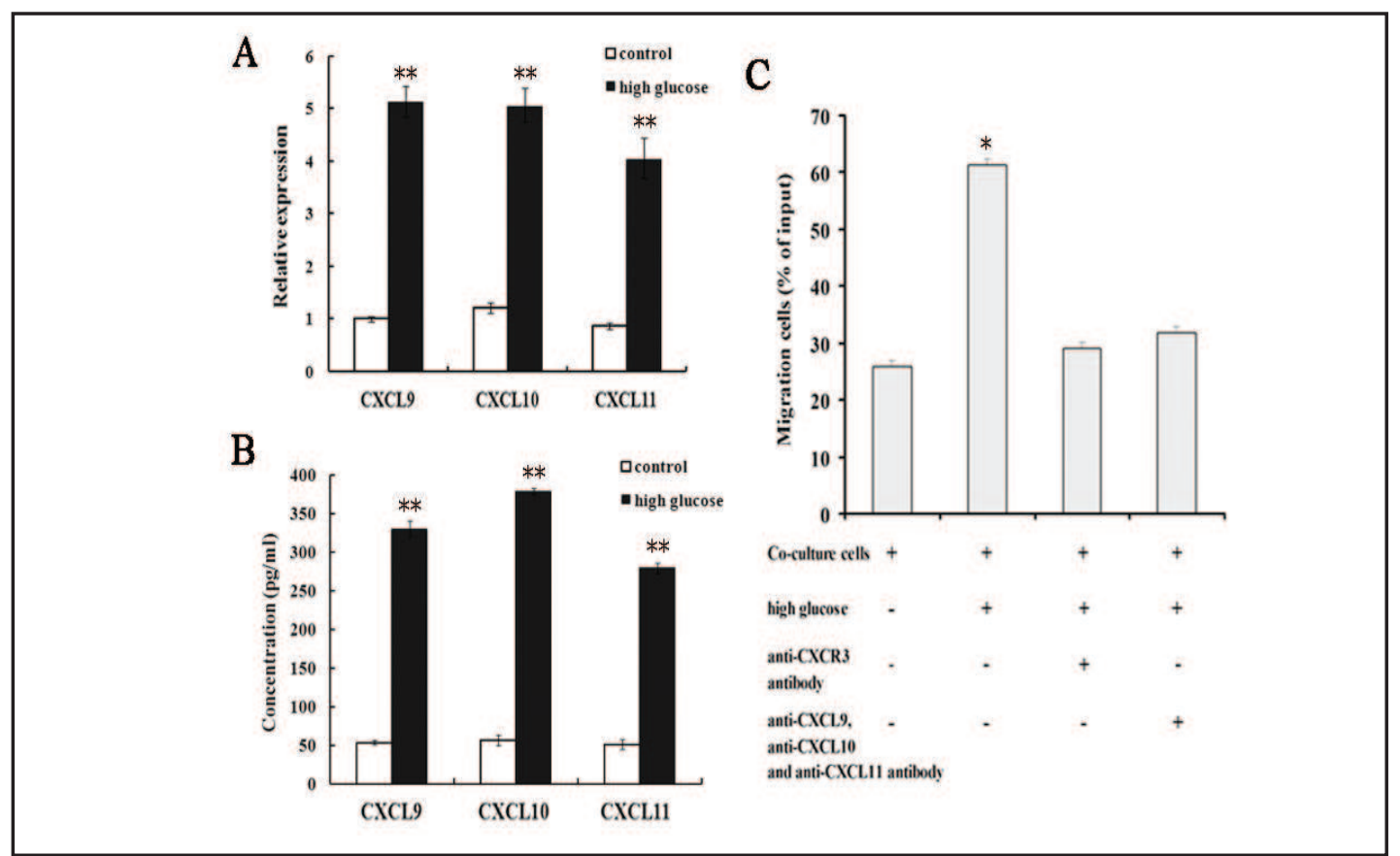

Fig. 4. (A) Schwann cells were stimulated with high glucose (50 mM) for 4 hours and the expression of CXCL9, CXCL10, and CXCL11 measured by quantitative real-time PCR. (B) Schwann cells were stimulated with high glucose (50 mM) for 48 hours, supernatants collected, and the level of CXCL9, CXCL10, and CXCL11 determined by ELISA. (C) Chemotaxis analysis was performed using the 96-well ChemoTx System. Chemotaxis medium containing a high concentration of glucose $(50 \mathrm{mM})$ was added to the lower chamber, and CD8 ${ }^{+}$T cells with $10 \mu \mathrm{g} / \mathrm{mL}$ IgG (or anti-CXCR3, anti-CXCL9, anti-CXCL10, and anti-CXCL11 antibodies were added into the upper chamber, which was separated from the lower chamber by an $8 \mu \mathrm{m}$ pore membrane. Chemotaxis was carried out at $37^{\circ} \mathrm{C}$ in a $5 \% \mathrm{CO}_{2}$ incubator. Four hours later, cells in the lower chamber were collected and counted. The ratio of migrating cells was calculated by dividing the number of cells in the lower chamber by the total number of input cells.

phosphorylation of p65, p38, pERK, and pJNK increased upon stimulation with high glucose concentrations (Fig. 2C). We blocked these pathways with specific inhibitors and found that the expression of CXCR3 mRNA was thoroughly abrogated with the inhibition of p38 but not with the inhibition of NF- $\mathrm{BB}$, ERK, and JNK (Fig. 2D). Flow cytometric analysis showed the same results (Fig. 2E). Taken together, our data indicate that high glucose levels induce CXCR3 expression in CD8 ${ }^{+} \mathrm{T}$ cells via p38 MAP kinase.

\section{CD8+ T cells infiltrate DPN tissues}

To determine the effects of high CXCR3 expression on $\mathrm{CD}^{+} \mathrm{T}$ cells, we investigated whether CXCR3 mediates the infiltration of $\mathrm{CD}^{+}{ }^{+} \mathrm{T}$ cells into DPN tissues. Peripheral nerve tissues from serious DPN lesions were obtained when surgery was applied for wound debridement. Frozen sections were cut, stained with CD8 and CXCR3, and examined under a confocal microscope. The data showed that an abundance of $\mathrm{CD}^{+} \mathrm{T}$ cells infiltrate DPN tissues and that these CD8 ${ }^{+} \mathrm{T}$ cells also express high levels of CXCR3 (Fig. 3), suggesting that CXCR3 may play an important role in the infiltration of $\mathrm{CD}^{+} \mathrm{T}$ cells into DPN tissues.

CXCL9, CXCL10, and CXCL11 from Schwann cells mediates the infiltration of CD8+ T cells into DPN tissues

As Schwann cells are reportedly involved in the development of DPN, we investigated whether Schwann cells have functions in the CXCR3-mediated infiltration of CD8 ${ }^{+} \mathrm{T}$ cells into DPN tissues. CXCL9, CXCL10, and CXCL11 are chemokines that recruit activated T cells into 


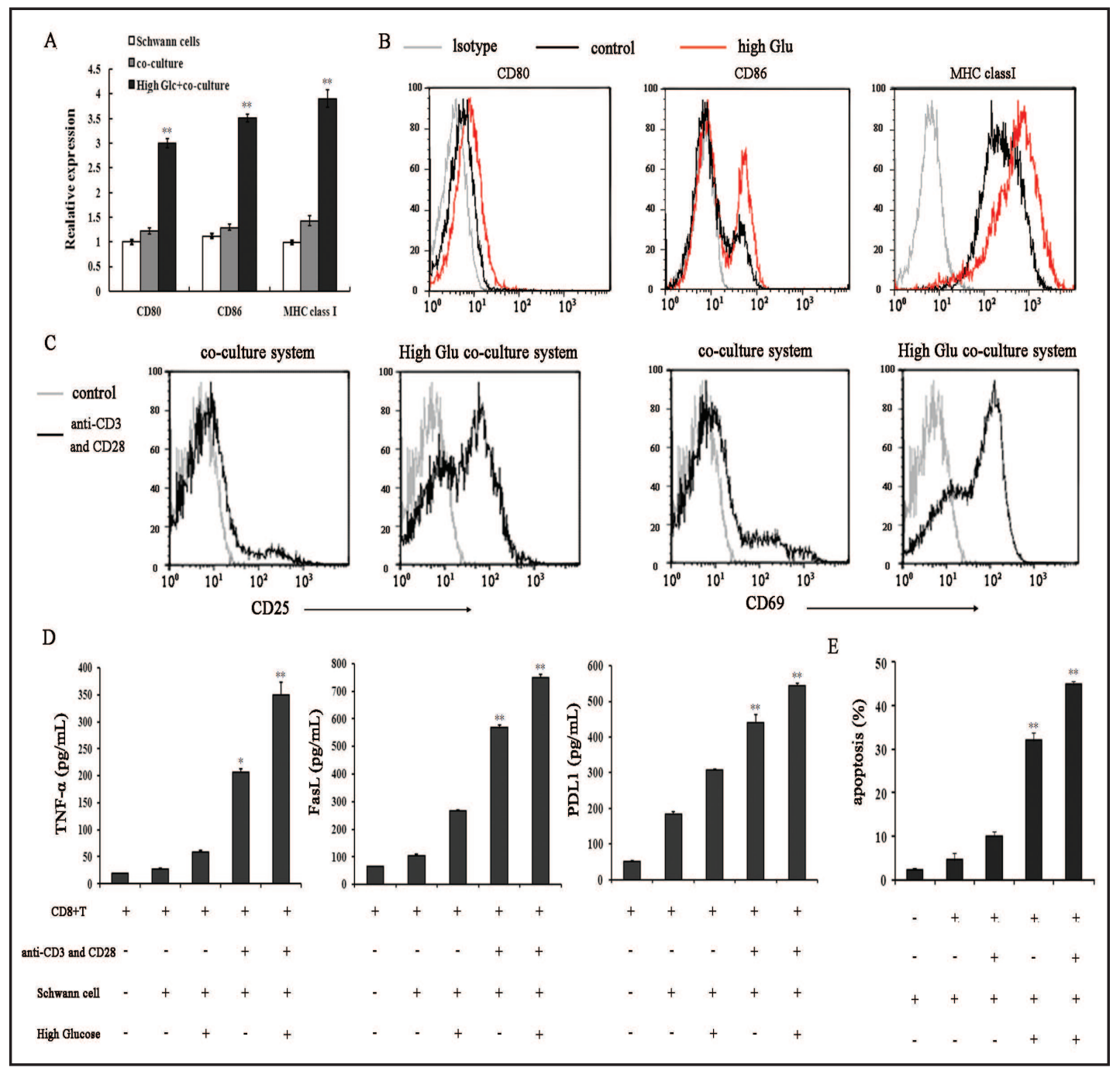

Fig. 5. Schwann cells were stimulated with a high concentration of glucose (50 $\mathrm{mM})$ for 4 hours, and the expression of MHC class I, CD80, and CD86 measured by (A) quantitative real-time PCR and (B) flow cytometry. Schwann cells were co-cultured with CD8+ T cells under high glucose levels in the presence of antiCD3 and anti-CD28 antibodies. (C) The expression of CD25 and CD69 was measured by flow cytometry. (D) CXCL9, CXCL10, and CXCL11 levels in the supernatants were determined by ELISA. (E) Schwann cells were stained with annexin V/PI to measure apoptosis.

inflammatory areas. We stimulated Schwann cells with high glucose levels and found that the mRNA expression of CXCL9, CXCL10, and CXCL11 were significantly elevated (Fig. 4A). Schwann cells were then cultured and stimulated with high glucose levels for 48 hours, the supernatants collected, and the protein levels of CXCL9, CXCL10, and CXCL11 determined by ELISA. The results showed that high glucose levels induce the vast production of CXCL9, CXCL10, and CXCL11 (Fig. 4B). Next, we performed transwell migration assays to investigate whether CXCL9, CXCL10, and CXCL11 derived from Schwann cells mediate the migration of $\mathrm{CD}^{+} \mathrm{T}$ cells. After 24 hours of incubation, Schwann cells cultured under high glucose levels induce an abundant migration of $\mathrm{CD}^{+} \mathrm{T}$ cells compared with normal glucose levels. The migration effect was blocked by the addition of anti-CXCR3, anti-CXCL9, anti-CXCL10, and anti-CXCL11 antibodies (Fig. 4C). Taken together, these findings suggest that CXCL9, CXCL10, and CXCL11 derived from Schwann cells mediate the infiltration of $\mathrm{CD}^{+} \mathrm{T}$ cells into DPN tissues through CXCR3. 


\section{Cellular Physiology and Biochemistry}

Cell Physiol Biochem 2013;32:827-837

\begin{tabular}{l|l}
\hline DOI: $10.1159 / 000354485$ & (C) 2013 S. Karger AG, Basel
\end{tabular}

www.karger.com/cpb

835

Tang et al.: CD8 ${ }^{+}$T Cell-Mediated Cytotoxicity toward Schwann Cells and DPN

\section{CD8 ${ }^{+}$T cells mediate cytotoxicity toward Schwann cells}

We investigated the interaction between Schwann cells and CD8 ${ }^{+} \mathrm{T}$ cells and found that high glucose levels also induce the upregulation of co-stimulating molecules (such as MHC class I, CD80, and CD86) in Schwann cells at the mRNA (Fig. 5A) and protein levels (Fig. 5B). To determine whether Schwann cells promote the activation of $\mathrm{CD}^{+} \mathrm{T}$ cells, we cocultured Schwann cells and $\mathrm{CD}^{+} \mathrm{T}$ cells under high glucose conditions in the presence of anti-CD3 and anti-CD28 antibodies, our data showed that CD8 ${ }^{+} \mathrm{T}$ cell activation was elevated in the presence of Schwann cells under high glucose levels (Fig. 5C). Moreover, we found that this co-culture induced the expression of TNF- $\alpha$, FasL, and PDL1 on CD8 ${ }^{+} \mathrm{T}$ cells (Fig. 5D). To determine whether CD8 ${ }^{+} \mathrm{T}$ cells were cytotoxic to Schwann cells, we found that CD8 ${ }^{+} \mathrm{T}$ cells obviously induce the apoptosis of Schwann cells under this co-culture system (Fig. 5E). Taken together, our results suggest that Schwann cells promote the activation of CD8 ${ }^{+} \mathrm{T}$ cells, which, in turn, mediates cytotoxicity toward Schwann cells.

\section{Discussion}

In this study, the high expression of CXCR3 on PBMCs was revealed through MALDI-TOFMS. We further demonstrated that high glucose levels induce CXCR3 expression on CD8 ${ }^{+} \mathrm{T}^{-}$ cells via the activation of p38 MAP kinases. High glucose levels also induced CXCL9, CXCL10, and CXCL11 expression in Schwann cells, which recruits an infiltration of CD8 ${ }^{+} \mathrm{T}$ cells into diabetic peripheral tissues through the CXCR3/CXCL9, CXCL10, and CXCL11 axis. These CD8 ${ }^{+}$ $\mathrm{T}$ cells mediate cytotoxicity toward Schwann cells and play a critical role in the development of diabetic peripheral neuropathy. Our study suggests that the blockade of the CXCR3/CXCL9, CXCL10, and CXCL11 axis in the inhibition of CD8 ${ }^{+} \mathrm{T}$ cell migration may be explored as a new strategy for preventing the development of diabetic peripheral neuropathy.

The hyperglycemic state is a major risk factor for the development of DPN and acts deleteriously via several pathways, including the adipose reduction pathway, the advanced glycation end product pathway, the reactive oxygen intermediate pathway and PKC pathway, and the Akt pathway [17-19]. These four pathways result in oxidant and inflammatory mediators that give rise to deleterious effects, both systemically and locally in tissues [16]. Activation of these pathways lead to the enhanced production of gluco-oxidants and the activation of signaling cascades by mediators such as mitogen-activated protein kinase and $\mathrm{NF}-\kappa \mathrm{B}$, thereby changing gene expression and/or protein functions that contribute to cellular dysfunctions [20]. In diabetes mellitus, hyperglycemia-induced oxidative stress activates p38 MAPK, which induces the phosphorylation of transcriptional factors, the altered expression of genes, and the production of fibronectin in mesangial cells, resulting in diabetic nephropathy $[8,21,22]$. In this study, we found that CXCR3 is upregulated in the CD8 ${ }^{+} \mathrm{T}$ cells of DPN patients. Further studies demonstrated that high glucose levels can induce CXCR3 expression on $\mathrm{CD}^{+} \mathrm{T}$ cells via the activation of p38 MAP kinase, indicating that $\mathrm{CD}^{+} \mathrm{T}$ cells may play a critical role in the pathogenesis of DPN.

Schwann cells are supportive gliocytes and peripheral myelin-forming cells in the peripheral nervous system. Hyperglycemia not only potentially damages Schwann cells, but also induces the expression of inflammatory cytokines and chemokines in Schwann cells [13, $23,24]$. Here we found that high glucose levels induce very high levels of several leukocyte chemokines which are ligands for the T cell-specific chemokine receptor CXCR3 on Schwann cells (most notably CXCL9, CXCL10, and CXCL11), which might contribute to the infiltration of $\mathrm{CD}^{+} \mathrm{T}$ cells into DPN tissues.

Diabetes is a major cause of peripheral neuropathy and is associated with changes in several metabolic and vascular mechanisms. In diabetes, macrophages activated by hyperglycemia can infiltrate into nerve tissues and locally produce neuropoietic cytokines, such as interleukin-1, interleukin-6, leukemia inhibitory factor, ciliary neurotropic factor, tumor necrosis factor, and transforming growth factor, resulting in endothelial and nerve fiber damage $[25,26]$. Macrophages have been found in the peripheral nervous system of 


\section{Cellular Physiology and Biochemistry}

Cell Physiol Biochem 2013;32:827-837

\begin{tabular}{l|l}
\hline DOI: $10.1159 / 000354485$ & (C) 2013 S. Karger AG, Basel
\end{tabular}

www.karger.com/cpb

Tang et al.: CD8 ${ }^{+} \mathrm{T}$ Cell-Mediated Cytotoxicity toward Schwann Cells and DPN

long-standing diabetic rats, insinuating themselves into the splitting myelin and assisting the demyelination process, probably participating in chemotaxis and nerve regeneration. Our results show that the infiltrated CD8 ${ }^{+}$T cells in DPN tissues led to damage to Schwann cells, suggesting that adaptive immune system participates in the development of DPN.

In conclusion, we demonstrate, for the first time, that high glucose levels induce the expression of CXCR3 on CD8 ${ }^{+} \mathrm{T}$ cells, and the expression of CXCL9, CXCL10, and CXCL11 on Schwann cells. This mediates the migration of $\mathrm{CD}^{+} \mathrm{T}$ cells into DPN tissues and causes damage to Schwann cells. Our study shows that the CXCR3/CXCL9, CXCL10, and CXCL11 axis in $\mathrm{CD}^{+} \mathrm{T}$ cells mediates the development of DPN, thus providing a new target for the treatment of DPN.

\section{Conflict of Interest}

All authors are in agreement with the content of this manuscript. The authors declare no conflicts of interest.

\section{Acknowledgments}

This research was supported by grants from the Natural Science Foundation of Shanghai (10ZR1439400) and Traditional Chinese medicine scientific research funds of Shanghai Municipal Health Bureau (2012J022A). Authors declare no financial or other relationships that might lead to a conflict of interest.

\section{References}

1 Sun LQ, Chen YY, Wang X, Li XJ, Xue B, Qu L, Zhang TT, Mu YM, Lu JM: The protective effect of alpha lipoic acid on schwann cells exposed to constant or intermittent high glucose. Biochem Pharmacol 2012;84:961973.

-2 Sun LQ, Xue B, Li XJ, Wang X, Qu L, Zhang TT, Zhao J, Wang BA, Zou XM, Mu YM, Lu JM: Inhibitory effects of salvianolic acid $\mathrm{b}$ on apoptosis of schwann cells and its mechanism induced by intermittent high glucose. Life Sci 2012;90:99-108.

-3 Edwards JL, Vincent AM, Cheng HT, Feldman EL: Diabetic neuropathy: Mechanisms to management. Pharmacol Ther 2008;120:1-34.

4 Sango K, Yanagisawa H, Takaku S, Kawakami E, Watabe K: Immortalized adult rodent schwann cells as in vitro models to study diabetic neuropathy. Exp Diabetes Res 2011;2011:374943.

5 Conti G, Scarpini E, Baron P, Livraghi S, Tiriticco M, Bianchi R, Vedeler C, Scarlato G: Macrophage infiltration and death in the nerve during the early phases of experimental diabetic neuropathy: A process concomitant with endoneurial induction of il-1beta and p75ntr. J Neurol Sci 2002;195:35-40.

6 Lee H, Jo EK, Choi SY, Oh SB, Park K, Kim JS, Lee SJ: Necrotic neuronal cells induce inflammatory schwann cell activation via tlr2 and tlr3: Implication in wallerian degeneration. Biochem Biophys Res Commun 2006;350:742-747.

7 Scholz J, Woolf CJ: The neuropathic pain triad: Neurons, immune cells and glia. Nat Neurosci 2007;10:13611368.

8 Cheng C, Qin Y, Shao X, Wang H, Gao Y, Cheng M, Shen A: Induction of tnf-alpha by lps in schwann cell is regulated by mapk activation signals. Cell Molecular Neurobiol 2007;27:909-921.

- Kamiya H, Murakawa Y, Zhang W, Sima AA: Unmyelinated fiber sensory neuropathy differs in type 1 and type 2 diabetes. Diabetes Metab Res Rev 2005;21:448-458. 


\section{Cellular Physiology and Biochemistry}

Cell Physiol Biochem 2013;32:827-837

\begin{tabular}{l|l}
\hline DOI: $10.1159 / 000354485$ & (c) 2013 S. Karger AG, Basel
\end{tabular}

10 Padilla A, Descorbeth M, Almeyda AL, Payne K, De Leon M: Hyperglycemia magnifies schwann cell dysfunction and cell death triggered by pa-induced lipotoxicity. Brain Res 2011;1370:64-79.

-11 Frigerio S, Junt T, Lu B, Gerard C, Zumsteg U, Hollander GA, Piali L: Beta cells are responsible for cxcr3mediated t-cell infiltration in insulitis. Nat Med 2002;8:1414-1420.

12 Nagai K, Fukushima T, Oike H, Kobori M: High glucose increases the expression of proinflammatory cytokines and secretion of tnfalpha and beta-hexosaminidase in human mast cells. Eur J Pharmacol 2012;687:39-45.

13 Huang W, Hu K, Luo S, Zhang M, Li C, Jin W, Liu Y, Griffin GE, Shattock RJ, Hu Q: Herpes simplex virus type 2 infection of human epithelial cells induces cxcl9 expression and cd4+ t cell migration via activation of p38ccaat/enhancer-binding protein-beta pathway. J Immunol 2012;188:6247-6257.

14 Jung EJ, Lee SY, Kim CW: Proteomic analysis of novel targets associated with trka-mediated tyrosine phosphorylation signaling pathways in sk-n-mc neuroblastoma cells. Proteomics 2013;13:355-367.

-15 Strohalm M, Kavan D, Novak P, Volny M, Havlicek V: Mmass 3: A cross-platform software environment for precise analysis of mass spectrometric data. Anal Chem 2010;82:4648-4651.

16 Kato A, Ogasawara T, Homma T, Batchelor J, Imai S, Wakiguchi H, Saito H, Matsumoto K: Cpg oligodeoxynucleotides directly induce cxcr3 chemokines in human b cells. Biochem Biophys Res Commun 2004;320:1139-1147.

17 Anitha M, Gondha C, Sutliff R, Parsadanian A, Mwangi S, Sitaraman SV, Srinivasan S: Gdnf rescues hyperglycemia-induced diabetic enteric neuropathy through activation of the pi3k/akt pathway. J Clin Invest 2006;116:344-356.

18 Martyn JA, Kaneki M, Yasuhara S: Obesity-induced insulin resistance and hyperglycemia: Etiologic factors and molecular mechanisms. Anesthesiology 2008;109:137-148.

19 Taguchi K, Kobayashi T, Matsumoto T, Kamata K: Dysfunction of endothelium-dependent relaxation to insulin via pkc-mediated grk2/akt activation in aortas of ob/ob mice. Am J Physiol Heart Circ Physiol 2011;301:H571-583.

20 Rolo AP, Palmeira CM: Diabetes and mitochondrial function: Role of hyperglycemia and oxidative stress. Toxicol Appl Pharmacol 2006;212:167-178.

21 Dave GS, Kalia K: Hyperglycemia induced oxidative stress in type-1 and type-2 diabetic patients with and without nephropathy. Cell Mol Biol (Noisy-le-grand) 2007;53:68-78.

-22 Chang YM, Shih YT, Chen YS, Liu CL, Fang WK, Tsai CH, Tsai FJ, Kuo WW, Lai TY, Huang CY: Schwann cell migration induced by earthworm extract via activation of pas and mmp2/9 mediated through erk1/2 and p38. Evid Based Complement Alternat Med 2011;2011:395458.

23 King GL: The role of inflammatory cytokines in diabetes and its complications. J Periodontol 2008;79:1527-1534.

24 Askwith T, Zeng W, Eggo MC, Stevens MJ: Oxidative stress and dysregulation of the taurine transporter in high-glucose-exposed human schwann cells: Implications for pathogenesis of diabetic neuropathy. Am J Physiol Endocrinol Metab 2009;297:E620-628.

25 Moalem G, Tracey DJ: Immune and inflammatory mechanisms in neuropathic pain. Brain Res Rev 2006;51:240-264.

26 Mert T, Gunay I, Ocal I, Guzel AI, Inal TC, Sencar L, Polat S: Macrophage depletion delays progression of neuropathic pain in diabetic animals. Naunyn Schmiedebergs Arch Pharmacol 2009;379:445-452. 